\title{
Models for Predicting Hydration Degree and Adiabatic Temperature Rise of Mass Concrete containing Ground Granulated Blast Furnace Slag
}

\author{
Arosha Dabarera $^{1, \mathrm{a}}$, Warangkana Saengsoy ${ }^{2, \mathrm{~b}, *}$, Krittiya Kaewmanee ${ }^{2}$, Kanako Mori ${ }^{3}$, \\ and Somnuk Tangtermsirikul ${ }^{1}$
}

1 School of Civil Engineering and Technology, Sirindhorn International Institute of Technology (SIIT), Thammasat University, Thailand

2 Construction and Maintenance Technology Research Center (CONTEC), School of Civil Engineering and Technology, Sirindhorn International Institute of Technology (SIIT), Thammasat University, Thailand 3 R\&D Department II, Central Research Laboratory, Taiheiyo Cement Corporation, Japan

E-mail: aaroshagp@gmail.com, bwarangkana@siit.tu.ac.th (Corresponding author)

\begin{abstract}
Predicting adiabatic temperature rise is essentially useful for investigating thermal cracking potential especially in early stage of mass concrete. Existing prediction methods and models have some problems such as constant thermal properties are mostly utilized for predicting temperature rise. This study is aimed to develop time-dependent models for predicting hydration degrees of cement and slag, free water amount, specific heat, and total heat generation of concrete incorporating slag. These models are then composed to predict the adiabatic temperature rise of mass concrete incorporating slag. The model is able to predict adiabatic temperature rise in mass concrete with different water to binder ratios, slag replacements, physical properties of slag, and initial temperature conditions. The validity of the proposed model was evaluated by comparing the model predictions with test results for adiabatic temperature rise of slag concrete. The model simulations can be used to predict the experimentally measured data from different sources.
\end{abstract}

Keywords: Adiabatic temperature rise, prediction model, mass concrete, slag, hydration degree.

ENGINEERING JOURNAL Volume 21 Issue 3

Received 18 April 2016

Accepted 17 October 2016

Published 15 June 2017

Online at http://www.engj.org/

DOI:10.4186/ej.2017.21.3.157 


\section{Introduction}

Hydration of cement generates heat since it is an exothermic reaction. This generated heat dissipates rapidly in concrete elements with relatively small dimension [1]. But, for massive concrete structures, the hydration process causes accumulation of heat inside the structures. The difference in temperature between center and surface of the mass concrete results in temperature gradient which leads to thermal cracking especially at early age [2-5]. Thermal cracking results in deterioration and reduces service life of concrete structures [1] Therefore, predicting temperature rise is beneficial for evaluating thermal cracking potential of mass concrete.

An effective way to reduce heat in mass concrete is using Supplementary Cementitious Materials (SCM's) due to their lower heat generation at early ages [1, 2, 5]. Ground Granulated Blast Furnace Slag (herein after referred as slag) is a SCM obtained as a by-product from steel manufacturing process. Slag shows both latent hydraulic and pozzolanic characteristics [6]. It can react with water in a slow rate and actively continues its pozzolanic reaction with portlandite which is produced from cement hydration. The practice of including slag as an SCM in concrete has gained attraction due to its engineering benefits such as low heat generation, low permeability and improvement of durability properties [7]. Slag is widely used in massive concrete structures to reduce the heat of hydration thus minimize thermal cracking potentials [8]. Therefore, understanding about hydration degrees of the cement-slag system is essentially beneficial for modeling thermal properties and evaluating cracking potential of mass concrete.

Hydration degree of cement is modeled in many studies since it is the governing process for prediction of various properties of concrete $[2,6,7]$. Kolani et al. [6] developed a hydration model for cement based on stoichiometric calculations by relating the chemical composition of the cement to that of their hydrated products. However, it was concluded that errors in the stoichiometry of hydrated products reduced the accuracy of this model. Wang and Lee [7] developed a kinetic model for predicting hydration degree of cement based on production and consumption of calcium hydroxide in concrete. However, the accuracy was limited as this model did not consider the effect of hydration of each reactive compound and influence of chemical and physical properties of binders. Saengsoy and Tangtermsirikul [2] developed a model for estimating hydration degree of cement by considering reactivity of each reactive compound in cement $\left(\mathrm{C}_{3} \mathrm{~A}\right.$, $\mathrm{C}_{3} \mathrm{~S}, \mathrm{C}_{2} \mathrm{~S}$, and $\left.\mathrm{C}_{4} \mathrm{AF}\right)$. An average hydration degree can also be estimated as a weight average of the hydration degrees of all reactive compounds in the cement. In the current study, this model is adopted to compute time-dependent hydration degree of cement.

Hydration degree of slag in paste may be experimentally obtained by several methods such as selective dissolution, recrystallization of slag from differential scanning calorimetry, cumulative heat evolution curves from isothermal calorimetry, and chemical shrinkage curves [9]. Among these tests, selective dissolution method is a comparatively simple, effective and accurate method to obtain hydration degree of slag. It is based on a preferential chemical dissolution of all the other products except unreacted slag [9-12]. The hydration degree can then be calculated based on the ratio between the reacted amount of slag per total amount of slag in the paste mixture. Lumley et al. [10] observed that hydration degree of slag significantly changes with age where at water to binder ratios (w/b) of $0.4-0.6$ and $20^{\circ} \mathrm{C}, 30-55 \%$ of slag reacts in 28 days and $45-75 \%$ in 1-2 years. Escalante et al. [12] investigated hydration degree of slag by selective dissolution method under different conditions. It was found that hydration degree of slag increases with temperature and w/b ratio, whereas, it decreases with increasing replacement level. Previous studies carried out in Japan $[11,13]$ observed that hydration degree increases as the fineness of slag increase indicating the importance of physical properties of the slag particles towards hydration. Analysing experimental results from selective dissolution method from different sources could be beneficial to develop a generalized model to quantitatively determine hydration degree of slag.

Several models have been developed to determine hydration degree of slag $[6,7,14,15]$. Kolani et al. [6] developed a model to quantify the hydration degree of slag in blended cement through the measurements of portlandite content, free water content and hydration heat. Wang and Lee [7] introduced a kinetic model to predict hydration degree of slag by considering the portlandite production by cement hydration and its consumption by slag. These models $[6,7]$ did not consider the influence of chemical compositions, and physical properties of cement and slag. Merzouki et al. [14] proposed another kinetic model based on stoichiometry of the reaction between slag and portlandite in which chemical composition of cement and slag, fineness, curing temperature and $\mathrm{w} / \mathrm{b}$ were taken into account. However, the model did not consider the time-dependent effect of free water and specific heat and also underestimated the portandite for high replacements of slag. Luan et al. [15] proposed a model to predict hydration degree 
considering the role of portlandite as the activator and the $\mathrm{Ca} / \mathrm{Si}$ ratio of $\mathrm{C}-\mathrm{S}-\mathrm{H}$. Time-dependent variation in total heat generation and specific heat were not considered in this model. Therefore, generalized model for quantification of reaction degree of slag by considering all the main factors and time-dependent variables is critical to determine the behaviour of slag in concrete.

If proper models for predicting hydration degree of cement and slag are established, investigation of thermal properties could be done for concrete containing slag. In the case of mass concrete, adiabatic temperature rise is vital since it is the most influential factor for thermal cracking potential [7]. Several investigations have been done to experimentally measure adiabatic temperature rise in mass concrete incorporating slag $[8,16]$. Models have been developed for predicting temperature rise and evaluating thermal cracking potential of mass concrete as well $[7,8,17]$. However, these models assumed constant specific heat values in their analysis to predict temperature in concrete.

In this study, generalized model to quantify time-dependent hydration degree of slag in concrete is proposed. The hydration degree of cement is adopted from a previous study [18] which is also timedependent. Then, models are proposed to predict thermal properties and adiabatic temperature rise for mass concrete containing slag. A time-dependent model for specific heat is introduced, enabling more accurate temperature simulation especially at early age of mass concrete. Specific heat is affected by the availability of free water in the concrete. Therefore, a time-dependent model for free water content is adopted to evaluate specific heat. The total heat generation is computed by summing up the heat liberated from reactions of all cement compounds, and slag. Thereby, adiabatic temperature rise in the centre of mass concrete can be computed based on the criteria that no heat loss to or gain from surrounding. If any interaction occurs between the concrete to or from surrounding, thermal conductivity involving rate of heat flow in concrete, heat transfer coefficients and other external effects are needed to be concerned. The verifications are done for the adiabatic temperature model by simulating adiabatic temperature profiles obtained from several sources of previously obtained experimental results.

\section{Model Formulation}

In the first part of this section, detailed explanation about the time-dependent models for predicting hydration degrees of cement and slag is presented. It is followed by the steps of modeling the adiabatic temperature rise in concrete containing slag. Models for hydration degree of cement, hydration degree of slag, free water content, specific heat and total heat generation of concrete are described separately. These models are linked to compute the adiabatic temperature rise from the Eq. (1).

$$
\Delta T=\frac{Q}{m c}
$$

where $\mathrm{Q}$ is the cumulative heat of hydration ( $\mathrm{kcal}), \mathrm{m}$ is mass of concrete $(\mathrm{kg}), \mathrm{c}$ is specific heat of concrete $\left(\mathrm{kcal} / \mathrm{kg} /{ }^{\circ} \mathrm{C}\right)$, and $\Delta \mathrm{T}$ is temperature rise at the considered age $\left({ }^{\circ} \mathrm{C}\right)$. The procedure for modeling adiabatic temperature rise of concrete in this study is summarized from the flowchart shown in Fig. 1 as follows. 


\section{Inputs: Initial temperature, Mix proportions, Necessary properties of} cement, slag, aggregates and water

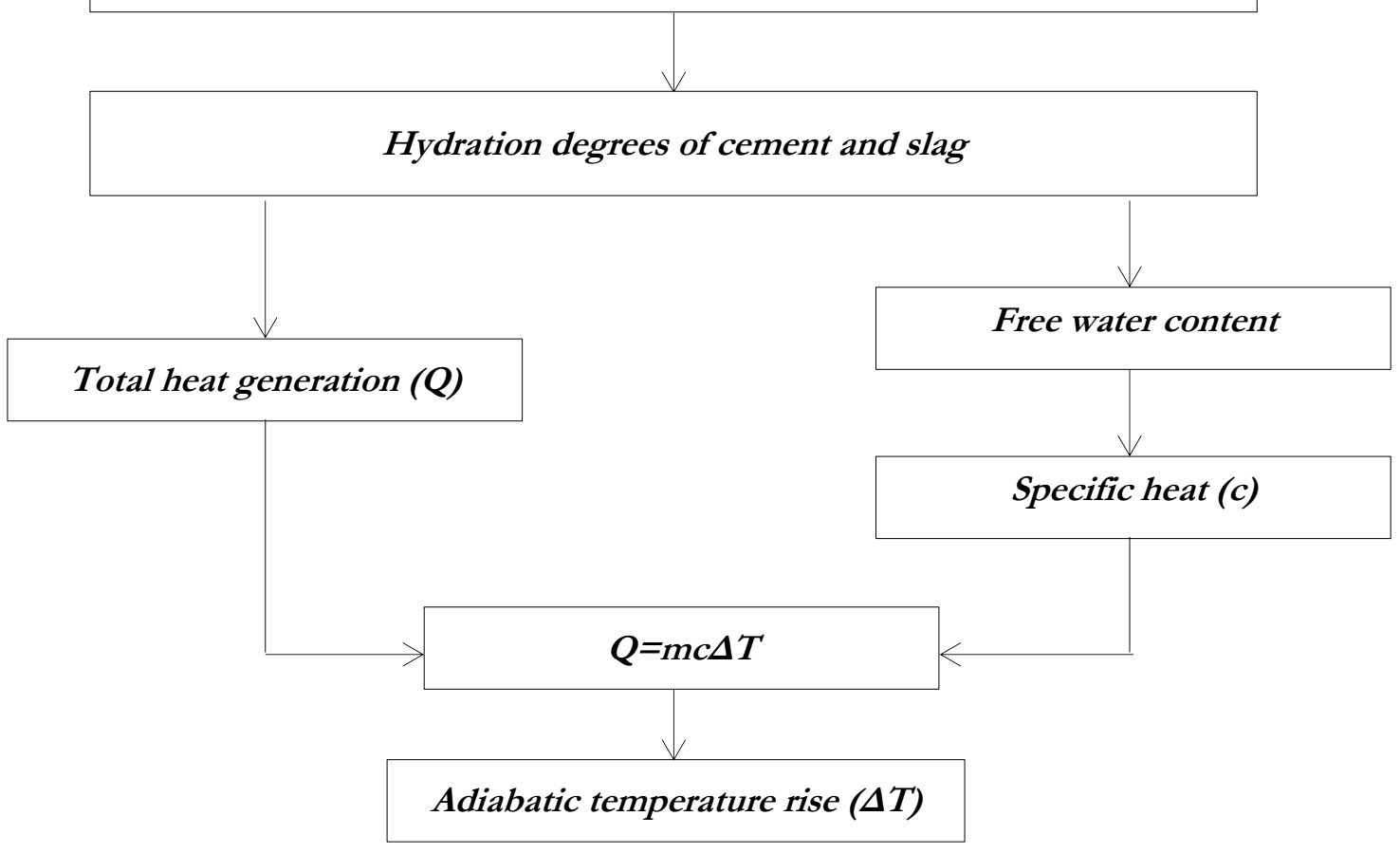

Fig. 1. Step-by-step procedure to compute adiabatic temperature rise in concrete.

\subsection{Model for Predicting Hydration and Average Hydration Degree of Cement}

In this model, hydration of each cement compound is computed separately. The equations for predicting the hydration degree of $\mathrm{C}_{3} \mathrm{~A}, \mathrm{C}_{3} \mathrm{~S}, \mathrm{C}_{2} \mathrm{~S}$, and $\mathrm{C}_{4} \mathrm{AF}$ are obtained from previous studies by Saengsoy and Tangtermsirikul $[2,18]$. The hydration degree which represents reaction rate is modeled as a function of age, water to cement ratio and concrete temperature. The average hydration degree is computed as a fraction of hydrated cement per total cement in the concrete mix. It is the summation of weighted average of hydration rates of all reactive cement compounds at the considered age. The proposed model for hydration degree of cement was verified and the predictions were satisfactory as previously reported in $[2$, 18]. Examples of simulation of average hydration degree of cement in slag-replaced concrete are shown in Fig. 2 and Fig. 3.

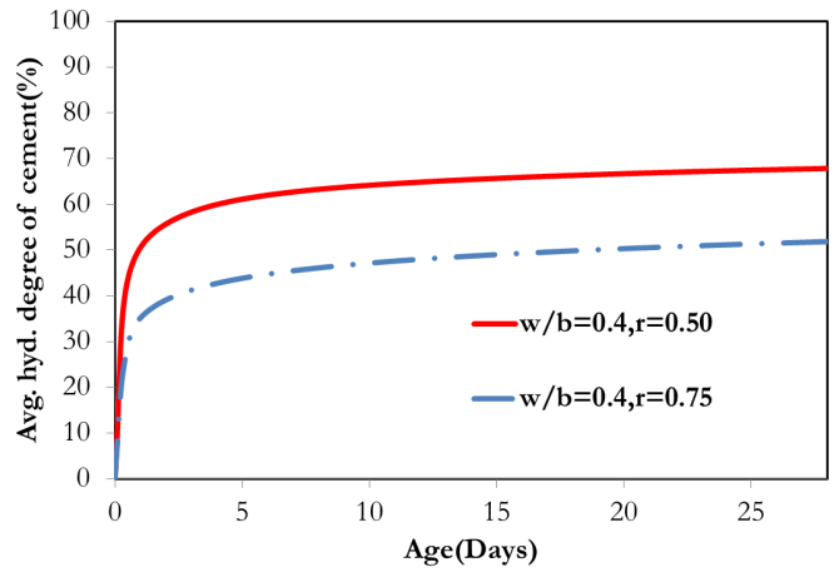

Fig. 2. Simulations of average hydration degree of cement in concrete with $w / b=0.4$ and slag replacements of $50 \%$ and $75 \%$. 


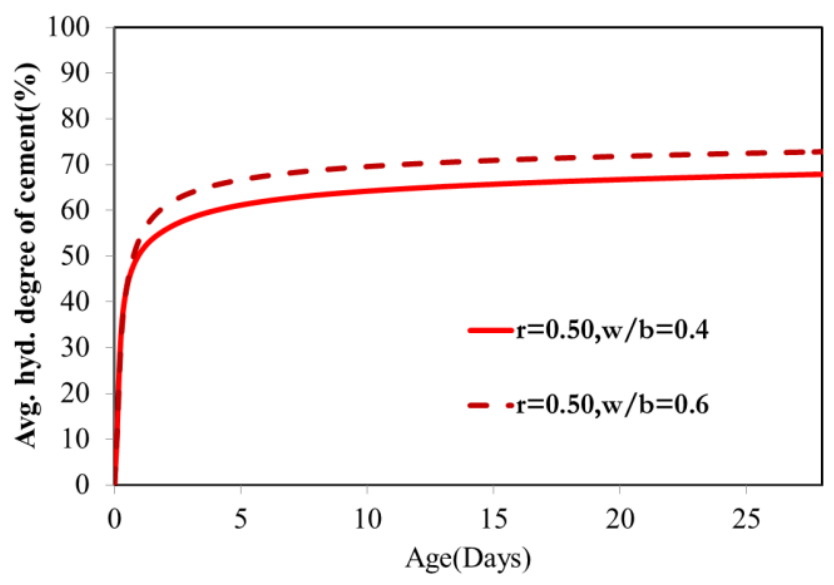

Fig. 3. Simulations of average hydration degree of cement in concrete with $50 \%$ slag replacement and water to binder ratios of 0.4 and 0.6 .

\subsection{Model for Predicting Hydration Degree of Slag}

The hydration degree of slag is defined as the weight fraction of already reacted slag per total slag in the concrete mix. As mentioned earlier, this can be obtained experimentally for paste by selective dissolution method. In this study, the main objective is to develop a time-dependent model for predicting hydration degree of slag in concrete. Analysis of selective dissolution data done only in paste samples is considered not possible to include the effect of fine and coarse aggregate in concrete. It is known that the presence of aggregate enhances the degree of reaction by providing a better mixing efficiency. Therefore, the model equation is obtained using the method of back analysis from adiabatic temperature results of slag concrete from K. Tada et al. [16]. However, the tendencies of previously obtained results from selective dissolution method by [10-13] are also studied to investigate the key parameters affecting the hydration degree of slag.

The key parameters of the model for predicting hydration degree of slag are age, water to binder ratio, concrete temperature, slag replacement ratio and fineness of the slag. The hydration degree increases as the $\mathrm{w} / \mathrm{b}$ of the paste increases. Addition of water results in higher contact between slag and water which leads to increased rate of formation of hydrated products [10]. This results in enhancing reactivity of slag. Considering the effect of temperature, as the temperature increases, the molecules move faster and collide more vigorously resulting in enhancing the hydration degree of slag [12]. Decrease in slag replacement percentage results in increasing the hydration degree of slag in cement paste. This occurs due to higher alkaline activating effect of the cement at lower concentrations of slag as previously reported in [12]. Fineness of the slag particles is another vital factor affecting the hydration degree of slag. It is reported that as the fineness increases, the hydration degree of slag increases due to higher contact area for the reaction to progress [13]. The model proposed in this study is based on the factors and similar tendencies with the results reported in [9-14], however, there is still lack of test results to compare the simulated hydration degree of slag in the case of concrete. The proposed equation for computing hydration degree of slag is shown in Eq. (2).

$$
\begin{aligned}
& \alpha_{\text {slag }}=a \times t^{b} \times r^{c} \times \operatorname{Exp}\left[d \times \alpha_{\text {slag }}(t-1)\right] \times\left[1+e \times \operatorname{Exp}^{*}(f \times w / b-g \times r) \times T\right] \times \\
& {\left[1+h \times\left(F_{\text {slag }}-3500\right)\right] \times[i \times T]^{\left(1+j \times w / b^{k}\right)}}
\end{aligned}
$$

where $\alpha_{\text {slag }}$ is the hydration degree of slag in concrete at the considered age. $\mathrm{t}, \mathrm{r}, \mathrm{w} / \mathrm{b}, \mathrm{T}$, and $\mathrm{F}_{\text {slag }}$ are the considered age (days), slag replacement ratio, water to binder ratio, initial temperature of concrete $\left({ }^{\circ} \mathrm{C}\right)$ and Blaine's fineness $\left(\mathrm{cm}^{2} / \mathrm{g}\right)$ of slag particles. Coefficients a, b, c, d, e, f, g, h, i, j, k and h are constants obtained from regression analysis $(\mathrm{a}=11.35, \mathrm{~b}=0.1, \mathrm{c}=0.45, \mathrm{~d}=-0.088, \mathrm{e}=0.018, \mathrm{f}=1.99, \mathrm{~g}=-2.3, \mathrm{~h}=0.00017$, $\mathrm{i}=0.043, \mathrm{j}=3.18, \mathrm{k}=2.1)$. The model is capable of predicting the hydration degree within the limits of slag replacement from $40 \%$ to $75 \%$, water to binder ratio from 0.35 to 0.65 , and slag fineness from $3500 \mathrm{~cm}^{2} / \mathrm{g}$ to $6000 \mathrm{~cm}^{2} / \mathrm{g}$. Examples of hydration degree simulations of slag in concrete are shown in Fig. 4 and Fig. 5 . 
The effect of slag replacement is indicated in Fig. 4 where an increase of the replacement results in decreasing the hydration degree of slag due to lower alkaline activating effect from cement as explained earlier. The effect of w/b is shown in Fig. 5 where an increase of w/b results in increasing the hydration degree of slag due to increased amount of hydrated products generated.

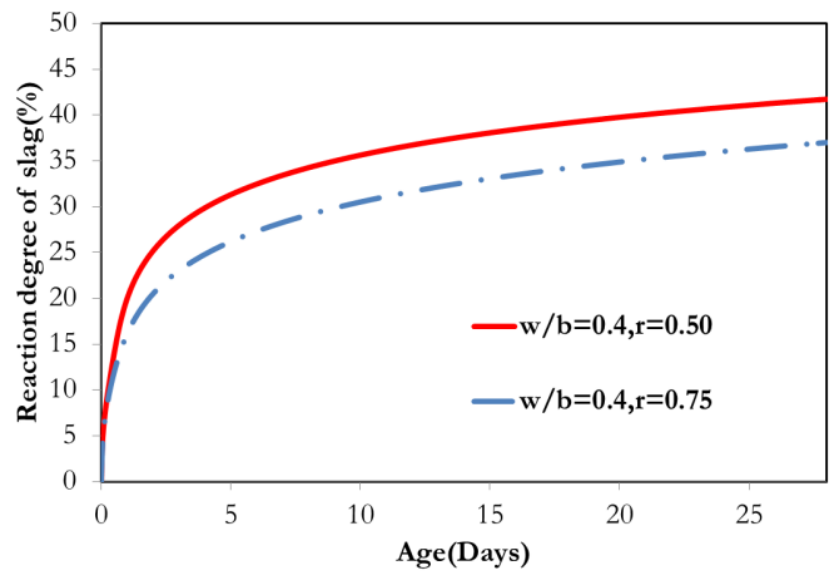

Fig. 4. Simulations of hydration degree of slag in concrete with $\mathrm{w} / \mathrm{b}=0.4$ and slag replacements of $50 \%$ and $75 \%$.

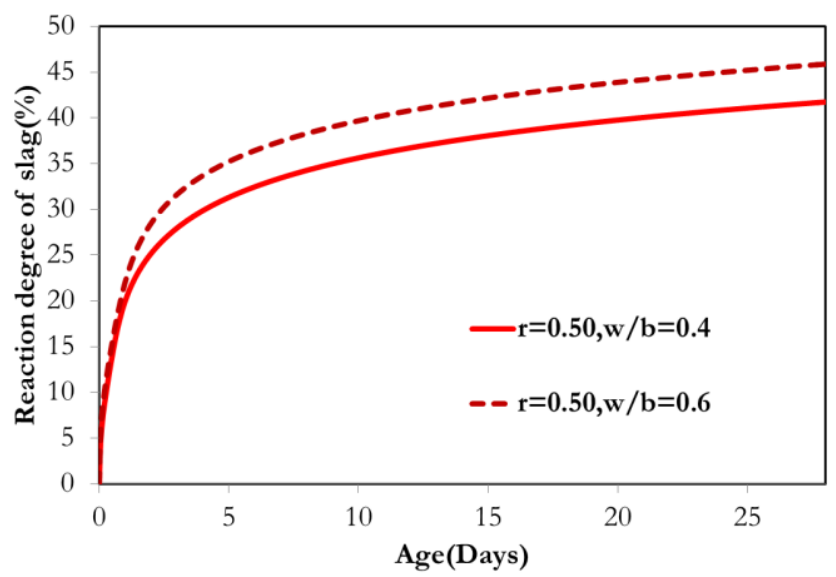

Fig. 5. Simulations of hydration degree of slag in concrete with $50 \%$ slag replacement and water to binder ratios of 0.4 and 0.6 .

\subsection{Effect of Physical Acceleration of Cement by Slag Particles}

The addition of slag can affect the cement hydration process. The reduction of cement content decreases the total heat generation in the presence of mineral admixtures $[1,4]$. However, it does not proportionally reduce the initial rate of heat evolution. This is due to the ability of the secondary fine particles to disperse cement particles $[7,19,20]$ denoted as a kind of physical acceleration. This physical acceleration effect was considered as an important factor in our previous studies for evaluating the effect of limestone powder and fly ash on cement hydration [19-21].

In the case of slag, Ogawa et al. [22] indicated that slag can accelerate the hydration of $\mathrm{C}_{3} \mathrm{~S}$ based on analysis from $\mathrm{C}_{3} \mathrm{~S}$-slag system using synthesized $\mathrm{C}_{3} \mathrm{~S}$ from reagents. S. Hoshino et al. [23] reported that slag accelerates the early age hydration of $\mathrm{C}_{3} \mathrm{~S}$ and $\mathrm{C}_{3} \mathrm{~A}$ from analysis of hydration degree of cement paste using combined X-ray diffraction and Rietveld analysis method. In this study, dispersion effect is considered to affect hydration degree of $\mathrm{C}_{3} \mathrm{~S}$ and $\mathrm{C}_{3} \mathrm{~A}$ in cement at very early age. However, its effect on hydration reactions at later age is insignificant. Equations for dispersion effect are proposed for acceleration of $\mathrm{C}_{3} \mathrm{~S}$ and $\mathrm{C}_{3} \mathrm{~A}$ hydration, by adopting a previous study by P. Choktaweekarn [20], as shown in Eq. (3) and Eq. (4), respectively. 


$$
\begin{aligned}
& \Phi_{C_{3} S}=-1.6612\left(\frac{\alpha_{C_{3} S}(t-1)}{100}\right)^{4}+3.8991\left(\frac{\alpha_{C_{3} S}(t-1)}{100}\right)^{3}-2.4864\left(\frac{\alpha_{C_{3} S}(t-1)}{100}\right)^{2} \\
& -0.2045\left(\frac{\alpha_{C_{3} S}(t-1)}{100}\right)+0.942 \times \tan ^{-1}\left[\left(F_{\text {slag }} \times\left(w_{c}+w_{\text {slag }}\right)\right)^{r}\right] \\
& \Phi_{C_{3} A}=1.0281\left(\frac{\alpha_{C_{3} A}(t-1)}{100}\right)^{4}-1.5095\left(\frac{\alpha_{C_{3} A}(t-1)}{100}\right)^{3}+0.4181\left(\frac{\alpha_{C_{3} A}(t-1)}{100}\right)^{2} \\
& -0.1354\left(\frac{\alpha_{C_{3} A}(t-1)}{100}\right)+0.78 \times \tan ^{-1}\left[\left(F_{\text {slag }} \times\left(w_{c}+w_{\text {slag }}\right)\right)^{r}\right]
\end{aligned}
$$

The hydration degrees of $\mathrm{C}_{3} \mathrm{~S}$ and $\mathrm{C}_{3} \mathrm{~A}$ are then multiplied by these 2 equations to take into account the physical acceleration effect as shown in Eq. (5) and Eq. (6), respectively.

$$
\begin{gathered}
\alpha_{C_{3} S, \bmod \text { ified }}=\alpha_{C_{3} S} \times \Phi_{C_{3} S} \\
\alpha_{C_{3} A, \bmod i \text { ifed }}=\alpha_{C_{3} A} \times \Phi_{C_{3} A}
\end{gathered}
$$

where $\Phi_{C 3 S}$ and $\Phi_{C 3 A}$ are the dispersion factors for $\mathrm{C}_{3} \mathrm{~S}$ and $\mathrm{C}_{3} \mathrm{~A}$ acceleration, respectively. $\mathrm{F}_{\text {slag }}$ is Blaine's fineness of slag powder $\left(\mathrm{cm}^{2} / \mathrm{g}\right)$. $\mathrm{w}_{\mathrm{c}}$ and $\mathrm{w}_{\text {slag }}$ are weight ratios of cement and slag per unit weight of concrete. $r$ is the replacement ratio of slag. $\alpha_{C 3 S}$ and $\alpha_{C 3 A}$ are hydration degrees of $C_{3} S$ and $C_{3} A$, respectively. $\alpha_{\mathrm{C} 3 \mathrm{~S} \text {,modified, }} \alpha_{\mathrm{C} 3 \mathrm{~A} \text {,modified }}$ are the modified hydration degrees of $\mathrm{C}_{3} \mathrm{~S}$ and $\mathrm{C}_{3} \mathrm{~A}$, respectively and $\mathrm{t}$ is the considered age in days.

\subsection{Free Water Content}

\subsubsection{Model for predicting free water content}

Water inside paste system can be classified into two main parts which are evaporable and non-evaporable water. Free water is defined as evaporable water which is freely accessible for hydration process [18]. This is a time dependent quantity since free water is consumed by hydration reactions of cement and slag. In this study, simulating free water content in pastes with slag is achieved by modifying a previously developed time-dependent model for fly ash paste system [2]. The modified equations are shown in Eq. (7), Eq. (8), and Eq. (9).

$$
\begin{gathered}
W_{f w}(t)=W_{f w 0}-W_{w h p}(t)-W_{\text {wgel }}(t) \\
W_{w h p}(t)=\theta_{h p, c} W_{u c 0} \frac{\alpha_{h y}(t)}{100}+\theta_{h p, s l a g} W_{u s l a g ~} \frac{\alpha_{\text {slag }}(t)}{100} \\
W_{\text {wgel }}(t)=\theta_{g e l, c} W_{u c 0} \frac{\alpha_{h y}(t)}{100}+\theta_{g e l, \text { slag }} W_{\text {uslag } 0} \frac{\alpha_{\text {slag }}(t)}{100}
\end{gathered}
$$

Free water is computed from Eq. (7), where $\mathrm{W}_{\mathrm{fw}}(\mathrm{t}), \mathrm{W}_{\mathrm{fw} w}, \mathrm{~W}_{\text {whp }}(\mathrm{t})$, and $\mathrm{W}_{\text {wgel }}(\mathrm{t})$ are the weights of free water $\left(\mathrm{kg} / \mathrm{m}^{3}\right)$, unit water content of the mix $\left(\mathrm{kg} / \mathrm{m}^{3}\right)$, weight of water consumed by hydration of cement and reaction of slag $\left(\mathrm{kg} / \mathrm{m}^{3}\right)$, and gel water content $\left(\mathrm{kg} / \mathrm{m}^{3}\right)$, respectively. Free water content in paste is reduced due to increase of water consumed by hydrations of cement and slag as well as increase of gel water content. The time-dependent weight of water consumed by hydrations of cement and slag can be

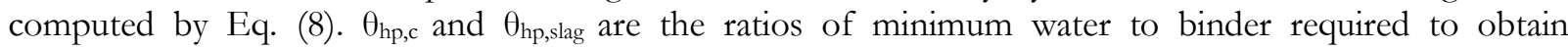
maximum reactions of cement and slag, respectively. The values of $\theta_{\mathrm{hp}, \mathrm{c}}$ and $\theta_{\mathrm{hp}, \mathrm{slag}}$ are 0.21 and 0.30 , obtained from previous studies $[7,18] . \mathbb{W}_{\text {wgel }}(t)$ is defined as the weight of gel water entrapped in products of hydration and can be calculated from Eq. (9). The equations for computing gel water in cement-slag 
system were obtained using a back analysis technique from our experimental data which is presented in section 2.4.2. $\theta_{\text {gel, }}$ is computed as a function of water to binder ratio whereas $\theta_{\text {gel, slag }}$ is computed as a function of water to binder ratio and slag replacement level. $W_{\text {uc } 0}, W_{\text {uslag } 0}, \alpha_{\text {hy }}(t)$ and $\alpha_{\text {slag }}(t)$ are the initial weight of cement $\left(\mathrm{kg} / \mathrm{m}^{3}\right)$, initial weight of slag $\left(\mathrm{kg} / \mathrm{m}^{3}\right)$, average hydration degree of cement $(\%)$ and hydration degree of slag (\%), respectively.

\subsubsection{Experimental procedure}

Free water content was experimentally obtained for paste incorporating slag by measuring the weight loss upon drying the specimens at $105^{\circ} \mathrm{C}$ for $24 \pm 2$ hours until the weight loss rate was less than $1 \%$ of the total weight of the specimen. A total of eight paste mixtures were cast to measure free water. Water to binder ratios of 0.25 and 0.40 were used. Slag replacements of $0 \%, 45 \%, 60 \%$, and $75 \%$ were utilized for each w/b. Mixture designations, w/b ratios, cement to binder ratios (c/b) and slag to binder ratios $(\mathrm{s} / \mathrm{b})$ are shown in Table 1. Specimens for free water content were cast in plastic cube molds with small dimensions of $20 \times 20 \times 40 \mathrm{~mm}$ to make sure that all free water can be removed, and were cured in a $28 \pm 2^{\circ} \mathrm{C} / 50-70 \% \mathrm{RH}$ condition until tested at 3,7 , and 28 days of age. The properties of the binders used in this experimental procedure are shown in Table 2.

Table 1. Mix proportions for measuring free water and specific heat capacity of paste.

\begin{tabular}{ccccccccc}
\hline Mix & W25 S0 & W25 S45 & W25 S60 & W25 S75 & W40 S0 & W40 S45 & W40 S60 & W40 S75 \\
\hline w/b & 0.25 & 0.25 & 0.25 & 0.25 & 0.40 & 0.40 & 0.40 & 0.40 \\
c/b & 1 & 0.55 & 0.40 & 0.25 & 1 & 0.55 & 0.40 & 0.25 \\
s/b & 0 & 0.45 & 0.60 & 0.75 & 0 & 0.45 & 0.60 & 0.75 \\
\hline
\end{tabular}

Table 2. Chemical compositions and physical properties of ordinary Portland cement type I and slag.

\begin{tabular}{|c|c|c|c|c|c|c|c|c|c|}
\hline \multirow[t]{2}{*}{ Binder } & \multicolumn{6}{|c|}{ Chemical compositions [ $\%$ by weight] } & \multirow{2}{*}{$\begin{array}{c}\text { Blaine's } \\
\text { fineness }\left[\mathrm{cm}^{2} / \mathrm{g}\right]\end{array}$} & \multirow{2}{*}{$\begin{array}{c}\text { Specific } \\
\text { gravity }\left[\mathrm{g} / \mathrm{cm}^{3}\right]\end{array}$} & \multirow{2}{*}{$\begin{array}{l}\text { Ignitior } \\
\text { loss[\%] }\end{array}$} \\
\hline & $\mathrm{SiO}_{2}$ & $\mathrm{Al}_{2} \mathrm{O}_{3}$ & $\mathrm{Fe}_{2} \mathrm{O}_{3}$ & $\mathrm{CaO}$ & $\mathrm{MgO}$ & $\mathrm{SO}_{3}$ & & & \\
\hline OPC & 20.0 & 5.40 & 3.0 & 63.4 & 2.7 & 2.0 & 3570 & 3.16 & 2.40 \\
\hline Slag & 33.5 & 14.35 & 0.26 & 43.3 & 5.1 & 2.1 & 4330 & 2.89 & 0.96 \\
\hline
\end{tabular}

\subsubsection{Test results and model simulations}

Figure 6 and Figure 7 show the experimentally obtained data and model predictions of free water to total binder ratios of paste containing slag at water to binder ratios of 0.25 , and 0.40 , respectively. It can be seen from both Fig. 6 and Fig. 7 that free water content decreases with time. A rapid decrease rate is observed especially at the early stage of the hardening process. This is due to water consumption by hydration reactions of cement and slag. Effect of w/b can be seen from Fig. 6 and Fig. 7 which indicate evident results that with higher $\mathrm{w} / \mathrm{b}$, free water is higher. The effect of slag is clearly shown for both $\mathrm{w} / \mathrm{b}$ cases where free water increases when the slag substitution level is higher. Similar results were previously reported by B. Kolani et al. [6]. This is due to lower reactivity of slag at early age when compared to cement. However, the decreasing rate of free water is higher at later age for paste with slag. At later age, the reaction of paste with slag increases. This is due to the activation of pozzolanic reaction of slag by $\mathrm{Ca}(\mathrm{OH})_{2}$ which is the product of hydration of cement. Therefore, as hydration of slag continues at later age, free water is reduced continuously as well.

Simulations were done from the proposed model as described earlier in this section. In order to verify the model, comparison between the computed results and the experimentally obtained results was conducted. The computed free water contents of pastes containing slag are shown in lines in Fig. 6 and Fig. 7 , whereas the test results are illustrated in dots. It is shown that the model is able to accurately predict the free water content of the tested paste specimens containing the tested slag. 


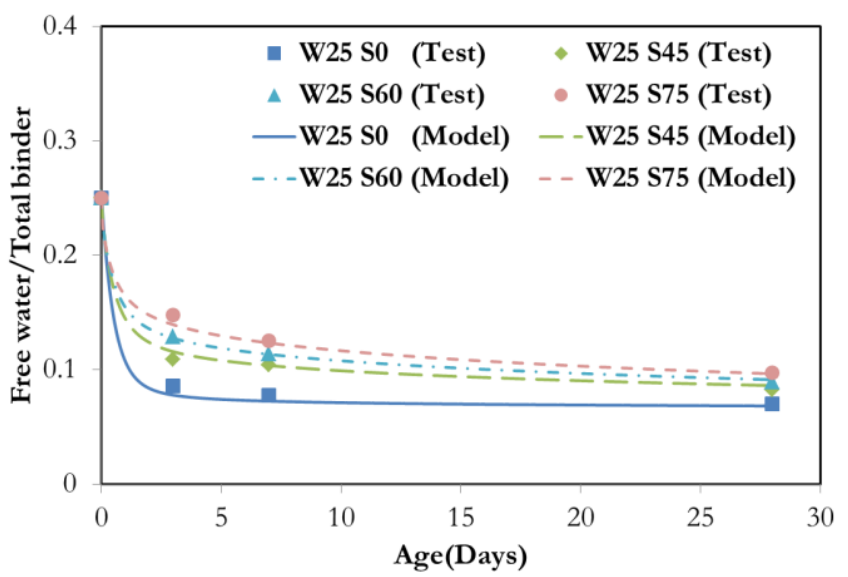

Fig. 6. Comparison of tested and predicted free water to total binder ratios of pastes with $0 \%, 45 \%, 60 \%$ and $75 \%$ slag and $w / b=0.25$.

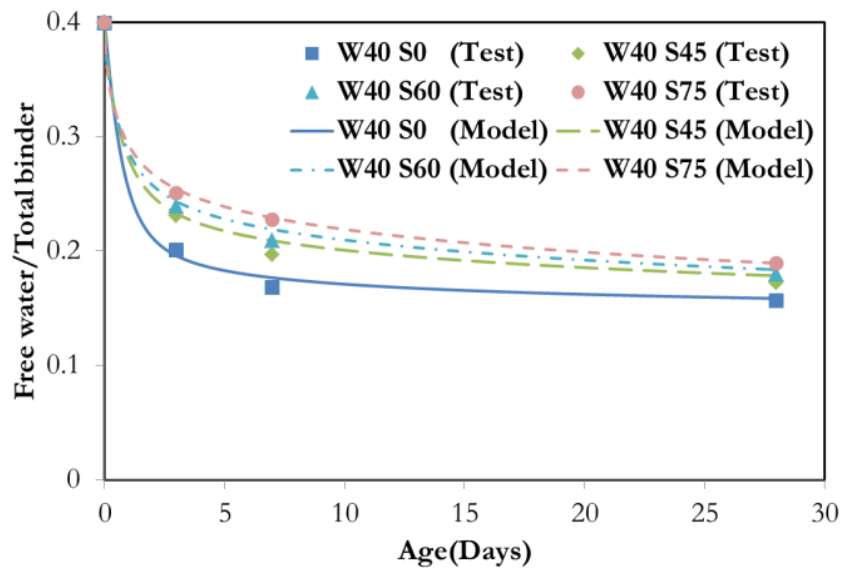

Fig. 7. Comparison of tested and predicted free water to total binder ratios of pastes with $0 \%, 45 \%, 60 \%$ and $75 \%$ slag and $\mathrm{w} / \mathrm{b}=0.40$.

\subsection{Specific Heat Capacity}

\subsubsection{Model for predicting specific heat capacity}

Specific heat is a time-dependent property which is changed rapidly especially at the early age after casting of concrete [24]. Modeling specific heat as a time-dependent variable is essentially useful for more accurate and precise predictions of temperature profiles. As the specific heat of water is the highest among all the constituents in concrete, specific heat of concrete is highly dependent on the free water content [19]. A previous study reported that specific heat of concrete at a given time can be calculated based on weight fraction of each constituent and their specific heat values [24]. This model is modified for the effect of slag to obtain specific heat capacity of paste, mortar and concrete. The modified equation is shown in Eq. (10).

$$
c(t)=w_{g} c_{g}+w_{s} c_{s}+w_{f w}(t) c_{w}+w_{u c}(t) c_{c}+w_{\text {uslag }} c_{\text {slag }}+w_{h p}(t) c_{h p}
$$

where $\mathrm{c}(\mathrm{t})$ is the specific heat of concrete at the considered age $\mathrm{t}\left(\mathrm{kcal} / \mathrm{kg} /{ }^{\circ} \mathrm{C}\right) . \mathrm{w}_{\mathrm{g}}$ and $\mathrm{w}_{\mathrm{s}}$ are the weight ratios of coarse and fine aggregates per unit weight of concrete, respectively. $\mathrm{w}_{\mathrm{fw}}(\mathrm{t}), \mathrm{w}_{\mathrm{uc}}(\mathrm{t}), \mathrm{w}_{\mathrm{uslag}}(\mathrm{t})$ and $\mathrm{w}_{\mathrm{hp}}(\mathrm{t})$ are the weight ratios of free water, unhydrated cement, non-reacted slag, and the hydrated products, respectively, at the considered age t. $c_{g}, c_{s}, c_{w}, c_{c}, c_{s l a g}$, and $c_{h p}$ are specific heat values of coarse aggregate, fine aggregate, water, cement, slag, and hydrated products, respectively $\left(\mathrm{kcal} / \mathrm{kg} /{ }^{\circ} \mathrm{C}\right)$. The value of $\mathrm{c}_{\text {slag }}$ is obtained from differential scanning calarimetry. Since all the other terms are known except the unknown $\mathrm{c}_{\mathrm{hp}}$, it is determined from back analysis from the test results of specific heat. The specific heat values of all constituents in concrete are shown in Table 3. 
Table 3. Specific heat values for each constituent of concrete.

\begin{tabular}{lcccccc}
\hline Constituents & Water $\left(\mathrm{c}_{\mathrm{w}}\right)$ & Cement $\left(\mathrm{c}_{\mathrm{c}}\right)$ & Slag $\left(\mathrm{c}_{\mathrm{slag}}\right)$ & $\begin{array}{c}\text { Fine agg. } \\
\left(\mathrm{c}_{\mathrm{s}}\right)\end{array}$ & $\begin{array}{c}\text { Coarse agg. } \\
\left(\mathrm{c}_{\mathrm{g}}\right)\end{array}$ & $\mathrm{c}_{\mathrm{hp}}{ }^{*}$ \\
\hline $\begin{array}{l}\text { Specific heat } \\
{\left[\mathrm{kcal} / \mathrm{kg} /{ }^{\circ} \mathrm{C}\right]}\end{array}$ & 1.00 & 0.18 & 0.17 & 0.19 & 0.20 & 0.08 \\
\hline${ }^{*}$ Specific beat of bydrated products is obtained from back analysis & & &
\end{tabular}

\subsubsection{Experimental procedure}

A total of eight mixtures were cast to obtain specific heat capacity of pastes similarly to those tested for free water content which is shown in Table 1. The properties of binders are mentioned in Table 2. Cube specimens with dimensions $50 \times 50 \times 50 \mathrm{~mm}$ were cast and were removed 24 hours after casting. Then these cubes were immediately wrapped firstly by a layer of plastic sheet followed by a layer of aluminum foil to prevent moisture loss to the environment. The specimens were cured in a $28 \pm 2{ }^{\circ} \mathrm{C} / 50-70 \% \mathrm{RH}$ condition until tested at 3, 7 , and 28 days.

Specific heat was experimentally obtained by a method based on transiently heated plane sensor using Hot Disk Thermal Constants Analyser, model type TPS 2500S. Transient measurement technique is appropriate for measurement of specific heat compared to steady state methods due to the rapidity of the test duration $[25,26]$. Thus, the measurement does not allow sufficient time for any moisture movement to occur within the sample during testing. In this test, a hot disk sensor was fitted between the two pieces of paste specimens with same mix proportions. Then the setup was covered with a sealed container to prevent moisture movement. An electrical current was passed high enough to increase temperature of the sensor and the resistance of the specimen was recorded simultaneously as a function of time. A Ni foil probe which was wrapped in Kapton was used in this experiment. Theoretical details of this method have been summarized by D.P. Bentz and Y. He [25, 26].

\subsubsection{Test results and model simulations}

Figure 8 and Figure 9 show the experimentally obtained data and model predictions of specific heat of pastes containing slag with water to binder ratios of 0.25 , and 0.40 , respectively. It is observed for both $\mathrm{w} / \mathrm{b}$ cases that specific heat significantly decreases with time especially at early age. The tendency was similar to that of the free water content since specific heat of water is the highest among all constituents in the paste as shown in Table 3. Effect of w/b can be seen from Fig. 8 and Fig. 9, which indicate that with higher $\mathrm{w} / \mathrm{b}$, specific heat values are higher as free contents are larger in mixtures with higher $\mathrm{w} / \mathrm{b}$. The values of early age specific heat of pastes containing slag are clearly higher than that of the cement paste. However, the specific heat of pastes containing slag continues to decrease in a higher rate when compared to that of the cement paste. This is due to the fact that hydration kinetics of slag increases at later age by activation of the pozzolanic reaction.

Simulations were done using the proposed model as described earlier in this section. In order to verify the model for specific heat, the computed specific heats were compared with the experimentally obtained results. The computed specific heats of pastes containing slag are shown in lines in Fig. 8 and Fig. 9 while the test results are given in dots. It is shown that the model is able to satisfactorily predict the specific heats of the tested paste specimens containing slag. 


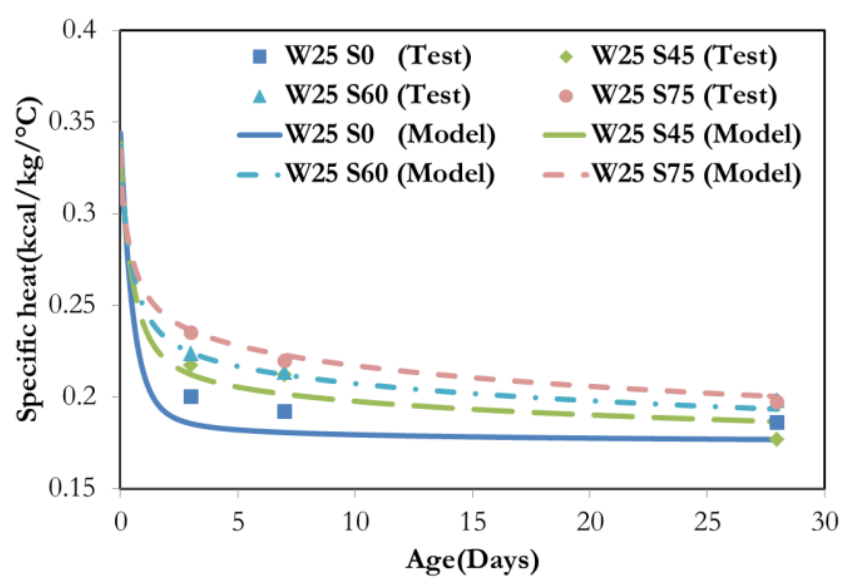

Fig. 8. Comparison of tested and predicted specific heat of pastes with $0 \%, 45 \%, 60 \%$ and $75 \%$ slag and $\mathrm{w} / \mathrm{b}=0.25$.

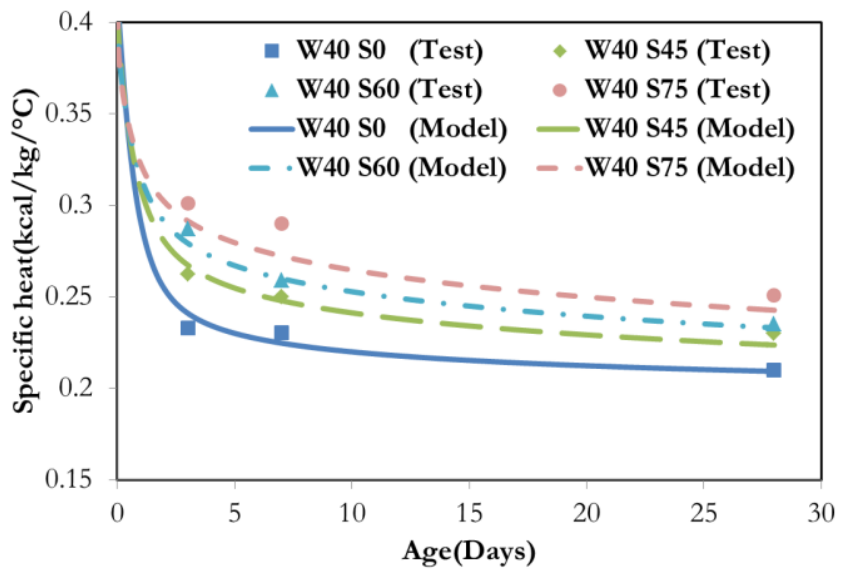

Fig. 9. Comparison of tested and predicted specific heat of pastes with $0 \%, 45 \%, 60 \%$ and $75 \%$ slag and $\mathrm{w} / \mathrm{b}=0.40$.

\subsection{Model for Predicting Total Heat Generation of Concrete}

The hydration of cement compounds and reaction of slag generate heat which results in temperature rise in concrete. The total heat generation is computed by including the effect of slag into a time-dependent model obtained from previous studies [5, 20]. The modified equations are shown in Eq. (11) and Eq. (12).

$$
\begin{gathered}
Q(t)=Q_{C_{3} S}(t)+Q_{C_{2} S}(t)+Q_{C_{3} A}(t)+Q_{C_{4} A F}(t)+Q_{C_{3} A E T}(t)+Q_{C_{4} A F E T}(t)+Q_{\text {Slag }}(t) \\
Q_{\text {Slag }}(t)=\left[\frac{\alpha_{\text {Slag }}(t)}{100}\right] \times Q_{\text {Slag, } \max } \times w_{\text {slag }}
\end{gathered}
$$

Total heat generation is computed from Eq. (11) where $Q(t)$ is the total heat generation of concrete $\left(\mathrm{kcal} / \mathrm{kg}\right.$ of concrete), $\mathrm{Q}_{\mathrm{C} 3 \mathrm{~S}}(\mathrm{t}), \mathrm{Q}_{\mathrm{C} 2 \mathrm{~s}}(\mathrm{t}), \mathrm{Q}_{\mathrm{C} 3 \mathrm{~A}}(\mathrm{t})$, and $\mathrm{Q}_{\mathrm{C} 4 \mathrm{AF}}(\mathrm{t})$ are cumulative heat generation of $\mathrm{C}_{3} \mathrm{~S}, \mathrm{C}_{2} \mathrm{~S}, \mathrm{C}_{3} \mathrm{~A}$, $\mathrm{C}_{4} \mathrm{AF}$ and slag, respectively (kcal/ $\mathrm{kg}$ of concrete). Q Q Сантт $(\mathrm{t})$ and $\mathrm{Q}_{\text {С4AFET }}(\mathrm{t})$ are heat generation from ettringite and monosulphate production by $\mathrm{C}_{3} \mathrm{~A}$ and $\mathrm{C}_{4} \mathrm{AF}$ reactions with gypsum, respectively $(\mathrm{kcal} / \mathrm{kg}$ of concrete). The details of the model can be found in our previous literature $[2,5,18,20]$.

Heat generation from reaction of slag is computed based on the degree of reaction and slag content in concrete and is shown in Eq. (12). Q Q slag $(t)$ is the cumulative heat generation from slag at the considered age $\mathrm{t}\left(\mathrm{kcal} / \mathrm{kg}\right.$ of concrete), $\alpha_{\text {Slag }}(\mathrm{t})$ is the reaction degree of slag (\%), Q Qlag,max is the maximum cumulative heat generation at completion of reaction of slag ( $\mathrm{kcal} / \mathrm{kg}$ of concrete), and $\mathrm{w}_{\text {slag }}$ is the mass fraction of slag in the concrete. In this study, the maximum cumulative heat generation from slag is estimated at $150 \mathrm{kcal} / \mathrm{kg}$ 
based on tendencies of heat rate in adiabatic temperature rise data obtained from K. Tada et al. [16]. It is slightly higher than the value proposed in a previous study [17] at $110 \mathrm{kcal} / \mathrm{kg}$.

Since the hydration degrees of cement and slag, free water content, specific heat and total heat generation of concrete are separately modeled, the models can be linked to compute the adiabatic temperature rise by using Eq. (1) as mentioned earlier.

\section{Verifications for the Proposed Adiabatic Temperature Simulation Model}

In order to validate the proposed model, verifications are carried out on concrete incorporating slag. Experimental data are obtained from two different sources $[7,16]$ to check the accuracy of the described model. Verifications for the experimental data obtained from X. Wang [7] are shown in Fig. 10 and Fig. 11. In this previous study, investigations are done for two different initial temperatures, $20^{\circ} \mathrm{C}$ and $30^{\circ} \mathrm{C}$. Comparison between the adiabatic temperature of concrete incorporating $40 \%$ slag with a water to binder ratio of 0.392 and another concrete mixture with $40 \%$ slag and water to binder ratio of 0.493 are shown in Fig. 10 and Fig. 11, respectively. Verification for results obtained by K. Tada et al. [16] which is for concrete incorporating $75 \%$ slag with water to binder ratios of 0.4 and 0.6 is shown in Fig. 12.

It is shown from these figures that the early age adiabatic temperature rise can be predicted with a certain accuracy. Slightly lower predictions at early age are observed in Fig. 11. These variations of the predictions are considered to be due to lack of consideration of effect of some certain compounds in cement which are not taken into account in this study. These compounds can alter the early age hydration rates of both cement and slag. Therefore, interaction of slag-cement behavior should be further investigated for an enhanced accuracy by also taking into consideration of some minor compounds. Moreover, the proposed model is to be further used for predicting thermal cracking of mass concrete structures and to investigate the efficiency of slag towards minimizing thermal cracking of concrete, which will be essentially useful for construction industry.

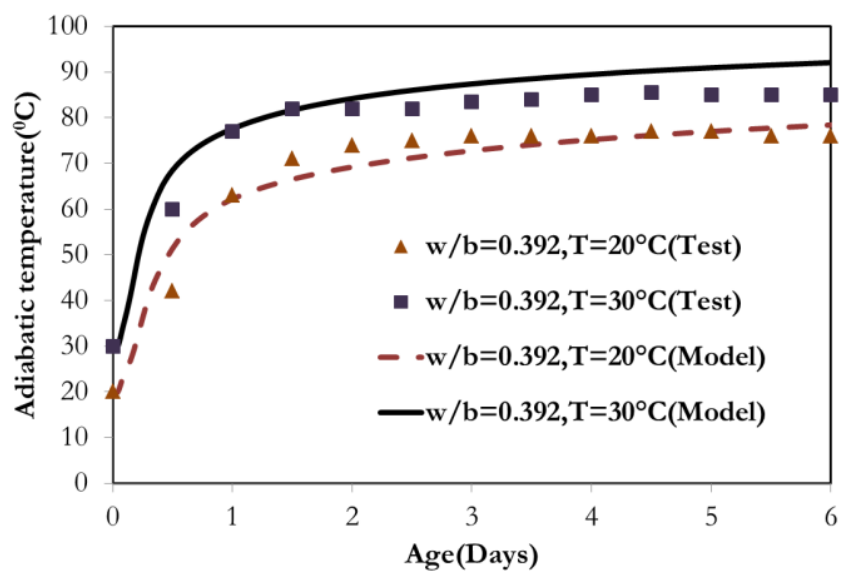

Fig. 10. Comparison of tested and predicted adiabatic temperature rise for concrete with $40 \%$ slag, $\mathrm{w} / \mathrm{b}=0.392$ and initial temperatures of $20^{\circ} \mathrm{C}$ and $30^{\circ} \mathrm{C}$. 


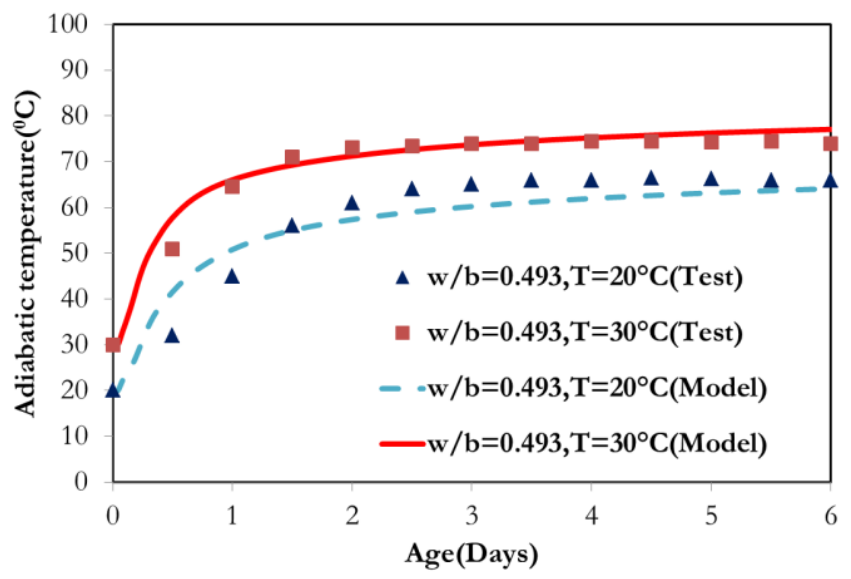

Fig. 11. Comparison of tested and predicted adiabatic temperature rise for concrete with $40 \%$ slag, $\mathrm{w} / \mathrm{b}=0.493$ and initial temperatures of $20^{\circ} \mathrm{C}$ and $30^{\circ} \mathrm{C}$.

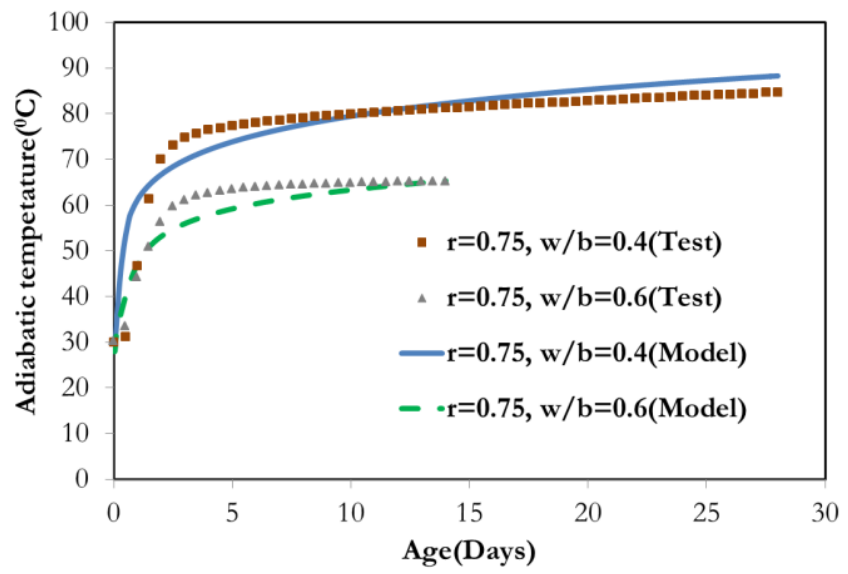

Fig. 12. Comparison of tested and predicted adiabatic temperature rise for concrete with $75 \%$ slag and water to binder ratios of 0.4 and 0.6 .

\section{Conclusions}

In this study, a model for predicting hydration degree and adiabatic temperature rise in mass concrete incorporating slag is proposed. Hydration degree of cement is computed based on reactions of $\mathrm{C}_{3} \mathrm{~A}, \mathrm{C}_{3} \mathrm{~S}$, $\mathrm{C}_{2} \mathrm{~S}$, and $\mathrm{C}_{4} \mathrm{AF}$ in concrete. Model for computing hydration degree of slag is proposed based on back analysis of temperature profiles of concrete containing slag and tendencies from previous results of selective dissolution method for slag-cement pastes. Hydration degree of slag is modeled as a function of age, water to binder ratio, concrete temperature, slag replacement level in concrete and fineness of slag. The physical acceleration of cement hydration by slag particles is considered by accommodating dispersion factors for $\mathrm{C}_{3} \mathrm{~S}$ and $\mathrm{C}_{3} \mathrm{~A}$ hydration into the model. Experiments are conducted to obtain free water content and specific heat of slag cement pastes. The results show that free water content significantly affects the specific heat of slag-cement pastes. This is due to the fact that specific heat of water is the highest among all other constituents in concrete. Based on these experiments, models are developed for computing free water content and specific heat for slag cement paste. Model for total heat generation is developed based on the summation of heat generated by all reactive compounds in concrete. All mentioned models in this study are linked to simulate adiabatic temperature rise in mass concrete. The model is expected to be able to predict adiabatic temperature rise in mass concrete with different water to binder ratios, slag replacement levels, physical properties of slag, and initial temperature conditions. In order to validate the proposed model, comparison between predictions from the model and test results for adiabatic temperature rise in previously tested mixtures of slag concrete are done. The proposed model can predict the experimental results obtained from different sources with a certain accuracy. Further enhancement of the model is to be done. 


\section{Acknowledgement}

The authors would like to acknowledge the Centre of Excellence in Material Science, Construction and Maintenance Technology, Thammasat University, Thailand and Taiheiyo Cement Corporation, Japan for the support and funding for this project. Moreover, acknowledgements are granted to the Higher Education Research Promotion and National Research University Project of Thailand, Office of the Higher Education Commission.

\section{References}

[1] A. Alhozaimy, G. Fares, O. A. Alawad, and A. Al-Negheimish, "Heat of hydration of concrete containing powdered scoria rock as natural pozzolanic material," Construction and Building Materials, vol. 81, no. 1, pp. 113-119, March 2015.

[2] S. Tangtermsirikul and W. Saengsoy, "Simulation of free water content of paste with with fly ash," Research and Development Journal of the Institute of Engineering Thailand, vol. 13, no. 4, pp. 1-10, 2002.

[3] Y. Ballim, "A numerical model and associated calorimeter for predicting temperature profiles in mass concrete," Cement \& Concrete Composites, vol. 26, no. 1, pp. 695-703, May 2003.

[4] M. Nili and A. M. Salehi "Assessing the effectiveness of pozzolans in massive high-strength concrete," Construction and Building Materials, vol. 24, no. 1, pp. 2108-2116, April 2010.

[5] P. Choktaweekarn and S. Tangtermsirikul, "Effect of aggregate type, casting, thickness and curing condition on restrained strain of mass concrete," Songklanakarin Journal of Science and Technology, vol. 32, no. 4, pp. 391-402, July 2010.

[6] B. Kolani, L. Buffo-Lacarriere, A. Sellier, G. Escadeillas, L. Boutillon, and L. Linger, "Hydration of slag-blended cements," Cement \& Concrete Composites, vol. 34, no. 1, pp. 1009-1018, June 2012.

[7] X. Y. Wang and H. S. Lee Linger, "Modelling the hydration of concrete incorporating fly ash or slag," Cement \& Concrete Research, vol. 40, no. 1, pp. 984-996, March 2010.

[8] A. Attari, C. McNally, and M. G. Richadson, "Numerical model for quantifying degree of hydration in concrete mixes with reduced $\mathrm{CO}_{2}$ footprint," Research Repository of University College Dublin, 2012.

[9] V. Kocaba, E. Gallucci, and K. L. Scrivener, "Methods for determination of degree of reaction of slag in blended cement pastes," Cement \& Concrete Research, vol. 42, no. 1, pp. 511-525, November 2011.

[10] J. S. Lumley, R. S. Gallop, G. K. Moir, and H. F. W. Taylor, "Degrees of reaction of the slag in some blends with Portland cements," Cement \& Concrete Research, vol. 26, no. 1, pp. 139-151, October 1996.

[11] S. Hanehara, N. Nito, K. Koibuchi, and T. Oyamada, "Quantitave analysis of slag content in anhydrous and hardening blast-furnace slag cement," Cement Science and Concrete Technology, vol. 64, no. 1, pp. 575-581, October 2014.

[12] J. I. Escalante, L. Y. Gomez, K. K. Johal, G. Mendoza, H. Mancha, and J. Mendez, "Reactivity of blast-furnace slag in Portland cement blends hydrated under different conditions," Cement \& Concrete Research, vol. 31, no. 1, pp. 1403-1409, June 2001.

[13] T. Sagawa and T. Nawa, "Quantitave determination of blast-furnace slag content in slag-blended cement by combination method of heat-treatment and XRD/Rietveld analysis," Cement Science and Concrete Technology, vol. 68, no. 1, pp. 38-45, March 2014.

[14] T. Merzouki, M. Bouasker, N. E. H. Khalifa, and P. Mounanga, "Contribution to the modeling of hydration and chemical shrinkage of slag-blended cement at early age," Construction and Building Materials, vol. 44, no. 1, pp. 368-380, February 2013.

[15] Y. Luan, T. Ishida, T. Nawa, and T. Sagawa, "Enhanced model and simulation of hydration process of blast furnace slag in blended cement," Journal of Advanced Concrete Technology, vol. 10, no. 1, pp. 1-13, May 2012.

[16] K. Tada, J. S. H. Lim, L. Doraipandian, T. Hayakawa, and S. Tanaka, "Experimental strength and heat evolution of concrete using fly ash in the Southeast Asian environment," in 6th International Conference of Asian Concrete Federation, Seoul, South Korea, 2014, pp. 272-275.

[17] S. Santhikumar, T. Kishi, and K. Maekawa, "Heat generation model for mixed Portland cement, blast furnace slag, and fly-ash concrete," in 4th East Asia-Pacific Conference on Structural Engineering and Construction, Tokyo, 1993, pp. 1449-1454. 
[18] W. Saengsoy and S. Tangtermsirikul, "Model for predicting temperature of mass concrete," presented at 4th Regional Symposium on Infrastructure Development in Civil Engineering, Bangkok, 2003.

[19] W. Saengsoy, S. Tangtermsirikul, and P. Jitvutikrai, "A study on specific heat of paste, mortar, and nofine concrete containing fly ash," Research and Development Journal of the Institute of Engineering Thailand, vol. 14, no. 2, pp. 19-26, 2003.

[20] P. Choktaweekarn and S. Tangtermsirikul, "Prediction of temperature of mass concrete with limestone powder," presented at National Convention on Civil Engineering, Chonburi, Thailand, 2011.

[21] T. Chuosavasdi, B. Stitmannaithum, T. Sumranwanich, W. Saengsoy, and S. Tangtermsirikul, "Degree of hydration and mass balance equations for determination of mix proportion of hardened OPC concrete," Engineering Journal, vol. 20, no. 2, pp. 211-219, May 2016.

[22] K. Ogawa, H. Uchikawa, K. Takemoto, and I. Yasui, "The mechanism of the hydration in the system C3S-pozzolana," Cement \& Concrete Research, vol. 10, no. 5, pp. 683-696, 1980.

[23] S. Hoshino, K. Yamada, and H. Hirao, "XRD/Rietveld analysis of the hydration and strength development of slag and limestone blended cement," Journal of Advanced Concrete Technology, vol. 4, no. 3, pp. 357-367, October 2006.

[24] P. Choktaweekarn, W. Saengsoy, and S. Tangtermsirikul, "A model for predicting the specific heat capacity of fly-ash concrete," ScienceAsia, vol. 35, no. 2, pp. 178-182, March 2009.

[25] D. P. Bentz, "Transient plane source measurements of the thermal properties of hydrating cement pastes," Materials and Structures, vol 40, no.1, pp. 1073-1080, January 2007.

[26] Y. He, "Rapid thermal conductivity measurement with a hot disk sensor Part 1. Theoretical considerations," Thermochimica acta, vol 436, no.1, pp. 122-129, June 2005. 